ISSN 1980-5098 @@ DOI: http://dx.doi.org/10.5902/1980509831567

\title{
AVALIAČ̃̃O DA PROPAGAÇÃO VEGETATIVA DE ESPÉCIES UTILIZADAS NA ESTABILIZAÇÃO DE OBRAS DE TERRA COM TÉCNICAS DE ENGENHARIA NATURAL
}

\author{
EVALUATION OF VEGETATIVE PROPAGATION OF SPECIES EMPLOYED IN EARTH- \\ WORK STABILIZATION WITH SOIL BIOENGINEERING TECHNIQUES
}

\author{
Fabrício Jaques Sutili $^{1}$ Rafael da Silva Dorneles ${ }^{2}$ Cristiane Ottes Vargas ${ }^{3}$ \\ Paula Letícia Wolff Kettenhuber ${ }^{4}$
}

\begin{abstract}
RESUMO
As técnicas de Engenharia Natural correspondem a um conjunto de ações que utilizam materiais de construção vivos, como plantas e estacas vivas, bem como materiais inertes, como elementos estruturais em construções bastante simples, com vistas à recuperação ecológica e à estabilização dos solos. Os materiais inertes utilizados, na dependência dos objetivos e da disponibilidade local, são basicamente estruturas metálicas, geotêxteis, madeira, pedras ou mesmo concreto. Esses, além de conferirem estabilidade imediata ao solo, oferecem proteção e suporte ao posterior desenvolvimento da vegetação. A parte vegetativa complementa, ou mesmo, gradativa e integralmente, substitui as funções estabilizadoras dos componentes inertes. No entanto, a execução dos trabalhos só pode ser realizada com sucesso quando as características técnicas da vegetação são conhecidas e, assim, corretamente aproveitadas. Esta pesquisa é o resultado de uma sequência de experimentos realizados com o objetivo de identificar, entre espécies de habitat ripário, aquelas com capacidade de propagação e desenvolvimento vegetativo. Uma grande parte dos modelos de intervenção utilizados pela Engenharia Natural vale-se exclusivamente dessa forma de propagação. Entre os muitos fatores potencialmente influentes no desenvolvimento vegetativo tais como sobrevivência, ritmo de enraizamento e de brotação, velocidade de crescimento de raízes e brotos deve-se também ressaltar a importância da época de coleta e plantio do material vegetal. Este estudo, utilizando-se de canteiros experimentais construídos em épocas distintas do ano, busca obter essas informações por meio da avaliação da sobrevivência e do desenvolvimento da parte aérea e radicular de estacas de seis espécies potenciais facilmente encontradas ao longo das margens fluviais dos rios do Sul do Brasil. As espécies testadas são: Calliandra brevipes, Phyllanthus sellowianus, Pouteria salicifolia, Salix humboldtiana, Salix x rubens e Sebastiania schottiana. Os resultados experimentais indicam a possibilidade de utilização de algumas dessas espécies. Calliandra brevipes, Sebastiania schottiana e Pouteria salicifolia apresentaram desenvolvimento inferior ao Phyllanthus sellowianus, Salix humboldtiana e Salix x rubens. Evidenciou-se que a época de plantio é menos importante em espécies de enraizamento rápido, como Phyllanthus sellowianus, Salix humboldtiana e Salix x rubens, mas pode ser decisiva em espécies com enraizamento mais lento, como Sebastiania schottiana, influenciando inclusive a sobrevivência da espécie.
\end{abstract}

Palavras-chave: Engenharia Natural; bioengenharia de solos; restauração ecológica; manejo de cursos de água.

1 Engenheiro Florestal, Dr., Professor do Departamento de Ciências Florestais, Centro de Ciências Rurais, Universidade Federalde Santa Maria, Av. Roraima, 1000, CEP 97105-900, Santa Maria (RS), Brasil. fjsutili@ gmail.com

2 Engenheiro Florestal, PL, BRF - Brasil Foods, Av. Senador Attílio Fontana, 600 E, CEP 89808-900, Chapecó (SC), Brasil.rafael.dornelles@sadia.com.br

3 Engenheira Florestal, Drª ., Fundação Estadual de Proteção Ambiental Henrique Luiz Roessler - FEPAM/RS, Av. Borges de Medeiros, 261, CEP 90020-021, Porto Alegre (RS), Brasil. cristiane_ov@yahoo.com.br

4 Engenheira Florestal, Msc., Doutoranda em Engenharia Florestal pelo Programa de Pós-Graduação em Engenharia Florestal, Centro de Ciências Rurais, Universidade Federalde Santa Maria, Av. Roraima, 1000, CEP 97105-900, Santa Maria (RS), Brasil. paulakettenhuber@gmail.com

Recebido para publicação em 17/02/2011 e aceito em 20/10/2016

Ci. Fl., v. 28, n. 1, jan.- mar., 2018 


\begin{abstract}
Soil bioengineering techniques use live construction materials like plants and live cuttings as well as inert materials as structural elements in simple constructions, with the purpose of ecological restoration and soil stabilization. The inert materials used depend on the aims and the local availability, are essentially metal structures, geotextiles, timber, stones or even concrete. These, in addition to provide immediate soil stabilization also supply protection and support for the further development of the vegetation. The vegetative part complements, gradually or entirely, replaces the functions of stabilizing inert components. However, construction works, can only be performed successfully when the vegetation technical characteristics are known and, thus, properly exploited. This research is the result of a sequence of experiments performed with the goal of identifying, among riparian inhabit species, those with vegetative propagation capacity and development. A large part of soil bioengineering models use exclusively that way of propagation. Among the many potentially influential factors in vegetative development, such as survival, rooting and sprouting rate, growth roots and shoots velocity, should be also highlighted, the importance of collecting and planting time for vegetation. Therefore, this study, using experimental plots built in different times of the year, seeks to obtain this information by assessing the survival rate, shoots and roots development using cuttings of six potential species easily found along stream banks in southern Brazil rivers. The tested species are: Calliandra brevipes, Phyllanthus sellowianus, Pouteria salicifolia, Salix humboldtiana, Salix x rubens and Sebastiania schottiana. The experimental results indicate the possibility of using some of these species. Calliandra brevipes, Sebastiania schottiana and Pouteria salicifolia presented lower development than Phyllanthus sellowianus, Salix humboldtiana and Salix x rubens. It was evidenced that the planting season, is less important in species with fast rooting, as Phyllanthus sellowianus, Salix humboldtiana and Salix $\mathrm{x}$ rubens, but can be decisive in species with slower rooting, such as Sebastiania schottiana, and can even have an effect on the survival rate of these species.
\end{abstract}

Keywords: soil bioengineering; ecological restoration; river and stream management.

\title{
INTRODUÇÃO
}

A erosão dos solos é um processo natural que tem seus efeitos negativos agravados devido ao manejo inadequado dos solos e da vegetação, principalmente em áreas mais propensas à sua ação, como encostas íngremes, margens de cursos de água e mesmo áreas planas, mas desprovidas de vegetação.

Os prejuízos decorrentes da erosão são potencialmente enormes, para Bertolini e Lombardi Neto (1994), a erosão implica diminuição da produção agrícola, menor cobertura do solo, redução da matéria orgânica e degradação física, química e biológica do solo. Segundo Pimentel et al. (1995), a erosão do solo é uma das maiores ameaças para o desenvolvimento sustentável e capacidade produtiva da agricultura, podendo até mesmo resultar em desmoronamentos e deslizamentos. Neste contexto, a vegetação desempenha um importante papel, pois pode, dentro de determinados limites, oferecer proteção ao solo e prevenir alguns dos problemas decorrentes dos movimentos de massa. Em um solo desprovido de proteção vegetal, ocorre menor armazenamento de água, maior escoamento superficial e, consequentemente, os rios tendem a receber grandes volumes de água (picos de vazão) e sedimentos (assoreamento), agravando os casos de corrosão das margens e deposições indesejadas, comuns aos trechos sinuosos e às baixadas fluviais (DURLO; SUTILI, 2005).

À medida que crescem os efeitos da erosão fluvial, a vegetação ciliar pode encontrar limitações de desenvolvimento e recomposição. Os efeitos negativos evoluem a tal ponto que corrosões e deslizamentos podem avançar até mesmo sobre áreas ainda vegetadas. Nas situações em que a área ribeirinha já se encontra desprovida de vegetação, o efeito da erosão é ainda mais agravado, o terreno se torna mais instável e também gradualmente mais íngreme, em consequência de sucessivos desconfinamentos. Nestes casos, o restabelecimento natural da vegetação se torna mais difícil ou mesmo impossível (VARGAS, 2007).

Dada a frequente impossibilidade de recuperação natural da vegetação, os trabalhos de remodelagem dos taludes e estabilização do solo, conjuntamente com o recobrimento vegetal induzido, se mostram necessários, a fim de contornar os inúmeros problemas ambientais, estéticos, econômicos e sociais, decorrentes dos impactos negativos da erosão e movimentos de massa em taludes fluviais. 
Avegetação pode ser utilizada de forma tecnicamente adequada, na solução dos casos de instabilidade de encostas e margens de cursos d'água, como reportam numerosos trabalhos sobre Engenharia Natural (GRAY; LEISER, 1982; SCHIECHTL, 1992; SCHIECHTL; STERN, 1994; MORGAN; RICKSON, 1995; FLORINETH, 2004; DURLO; SUTILI, 2005; DENARDI, 2007).

A Engenharia Natural constitui um conjunto de técnicas em que materiais inertes e plantas vivas, ou partes destas, são utilizados como material de construção. Nessas técnicas, não só os materiais inertes como madeira, pedras, geotêxteis e estruturas de metal e concreto, mas também a vegetação é entendida como componente construtivo estrutural em obras que visam à perenização de cursos de água, à estabilização de encostas, ao tratamento de voçorocas e ao controle da erosão. Para o sucesso de tais trabalhos deve-se não só empregar os modelos de intervenção adequados a cada caso, mas especialmente, possuir conhecimento das características técnicas da vegetação, com vistas a seu correto aproveitamento (SUTILI; DURLO, 2007).

As principais características da vegetação a serem consideradas para a utilização em intervenções no ambiente fluvial são: 1 - a morfometria e a flexibilidade da parte aérea; 2 - a capacidade e o ritmo de propagação vegetativa; 3 - a velocidade do crescimento da brotação; 4 - a arquitetura e a velocidade de crescimento do sistema radicular.

$\mathrm{O}$ aspecto reprodutivo tem grande importância nos trabalhos de Engenharia Natural. As plantas devem possuir uma forma de reprodução fácil e econômica. Normalmente, plantas com capacidade de reprodução vegetativa são as ideais para vários dos métodos construtivos empregados, embora isso não exclua aquelas que só se propagem por meio de sementes. Assim como a propagação via seminal, aquela realizada vegetativamente também é particular de cada espécie e seu sucesso se modifica em função da época do ano em que a coleta e o plantio do material forem realizados.

A propagação vegetativa é a forma de reprodução preferencial na $\mathrm{EN}$, uma vez que os ramos, especialmente se empregados em construções como a esteira-viva, entrançados-vivos, feixes-vivos ou plantados densamente em banquetas, podendo contribuir para reforço físico imediato na proteção e estabilização do solo, antes mesmo que tenha havido enraizamento e brotação (SAULI; CORNELINI; PRETI, 2002; ABATE; GROTTA, 2009; MENEGAZZI; PALMERI, 2013). Dito de outra forma, o próprio Dito de outra forma, o próprio material vegetal empregado na propagação pode melhorar as propriedades de engenharia do solo, ou diminuir a solicitação sobre estes. Mesmo com estacas singulares, a propagação vegetativa se mostra interessante, pois é de maior praticidade e menor custo quando comparada ao uso de mudas, além de poder ser com maior facilidade combinada a materiais inertes como gabiões, pedras, estruturas de concreto ou geotêxteis.

Algumas das intervenções (físicas) necessárias na implantação das obras de Engenharia Natural podem ser melhor ou mesmo unicamente realizadas no momento em que os cursos d'água se encontram com seu menor volume de água. O excesso de chuva além de dificultar as intervenções físicas necessárias, traz maior risco à obra. Justificando a importância de se usar métodos que sejam capazes de conferir estabilidade. Daí a importância de se usarem métodos que sejam capazes de conferir estabilidade inicial logo após sua implantação e espécies que tenham ritmo vegetativo capaz de, em pouco tempo, contribuir com a estabilidade do local. Outra solução seria reconhecer espécies que possuam capacidade de reprodução vegetativa fora do período de maior precipitação.

O período de coleta das estacas pode ter um papel importante na capacidade de enraizamento. Segundo Komissarov (1968) apud Rezende (2007), a época do ano em que a estaquia é realizada, é fator determinante do sucesso, já que está relacionada com o estádio do ramo e com o grau de atividade dos processos fisiológicos das plantas. Dessa forma, algumas plantas podem ser propagadas no período de crescimento e outras durante o repouso. A época ideal para a propagação de cada planta em especial deve ser determinada regionalmente e experimentalmente.

O presente trabalho tem o objetivo de subsidiar a seleção de espécies potenciais para aplicação em técnicas de Engenharia Natural através da apresentação e análise de informações sobre o desenvolvimento vegetativo das espécies Calliandra brevipes, Phyllanthus sellowianus, Pouteria salicifolia, Salix humboldtiana, Salix x rubens e Sebastiania schottiana, sendo estas de hábito reconhecidamente reófito e facilmente encontradas nas margens de rios e arroios da Depressão Central do Estado do Rio Grande do Sul. 


\section{MATERIAIS E MÉTODOS}

O desenvolvimento vegetativo das seis espécies foi avaliado através da taxa de sobrevivência e a produção de brotos e raízes durante cinco meses, a partir de três canteiros experimentais (Tabela 1), implantados em três diferentes épocas do ano.

TABELA 1: Espécies avaliadas (marcadas com X) nos respectivos Canteiros Experimentais e em diferentes períodos do ano.

TABLE 1: Assessed species (marked with X) in their Experimental Plots and in different periods of the year.

\begin{tabular}{|c|c|c|c|c|c|c|c|c|}
\hline \multicolumn{3}{|c|}{ Canteiros Experimentais } & \multicolumn{6}{|c|}{ Espécies Avaliadas } \\
\hline Local & Canteiros & Período (Estação do ano) & 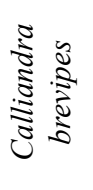 & 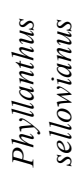 & 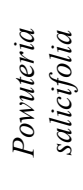 & 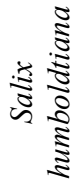 & 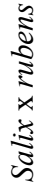 & 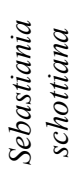 \\
\hline $\begin{array}{l}\text { Arroio Guarda-mor no } \\
\text { município de Faxinal do } \\
\text { Soturno }\end{array}$ & 1 & $\begin{array}{c}11 / 4 \text { a } 9 / 9 / 2003 \\
\text { (outono e inverno) }\end{array}$ & $X$ & $\mathrm{X}$ & & $\mathrm{X}$ & & $X$ \\
\hline \multirow{2}{*}{$\begin{array}{c}\text { Estação de Silvicultura no } \\
\text { campus da UFSM em Santa } \\
\text { Maria }\end{array}$} & 2 & $\begin{array}{l}20 / 2 \text { a } 17 / 7 / 2004 \\
\text { (verão e outono) }\end{array}$ & & $\mathrm{X}$ & $X$ & $\mathrm{X}$ & $X$ & $X$ \\
\hline & 3 & $\begin{array}{l}\text { 4/9/2004 a 5/2/2005 } \\
\text { (final do inverno, } \\
\text { primavera, início do } \\
\text { verão) }\end{array}$ & & $\mathrm{X}$ & & & $\mathrm{X}$ & $\mathrm{X}$ \\
\hline
\end{tabular}

Calliandra brevipes, Phyllanthus sellowianus, Salix humboldtiana e Sebastiania schottiana foram avaliadas de 11 de abril a 9 de setembro de 2003, no canteiro experimental implantado às margens do Arroio Guarda-mor, sendo esse trabalho parte dos estudos realizados por Altreiter e Plunger (2004) publicados na integra como monografia de final de curso apresentada ao Instituto de Engenharia Natural da Universidade Rural de Viena. No segundo momento (20 de fevereiro a 17 de julho de 2004) foram reavaliadas as espécies: Phyllanthus sellowianus; Salix humboldtiana e Sebastiania schottiana, as quais apresentaram os melhores resultados na $1^{\mathrm{a}}$ avaliação e também incluídas Pouteria salicifolia e Salix x rubens, agora em área do campus universitário da Universidade Federal de Santa Maria. Por fim, no período compreendido entre 4 de setembro de 2004 a 5 de fevereiro de 2005, apenas as espécies Phyllanthus sellowianus, Salix x rubens e Sebastiania schottiana foram reavaliadas, uma vez que as mesmas apresentaram os melhores resultados nas avaliações anteriores.

A metodologia de implantação e condução dos experimentos, descrita por Florineth e Gerstgraser (2000) com base nos trabalhos pioneiros de Schiechtl (1973), experimentos que visam avaliar o desenvolvimento vegetativo de plantas para utilização.

\section{Implantação dos Canteiros Experimentais}

Inicialmente, o canteiro foi construído a poucos metros do nível normal das águas do Arroio Guardamor, com solo retirado das suas margens instáveis. Para o segundo e terceiro canteiro, o solo foi transportado do mesmo local para a Estação de Silvicultura no campus da UFSM. A análise das características básicas do solo é apresentada na Tabela 2.

O solo utilizado nos canteiros apresenta acidez elevada, altas concentrações de alumínio, baixo teor de matéria orgânica, P limitante e K muito baixo, fatores que podem ser restritivos ao crescimento das plantas (COMISSÃO DE QUÍMICA E FERTILIDADE DO SOLO, 2004). No entanto, de acordo com Schiechtl (1973), experimentos que visem avaliar o desenvolvimento vegetativo de plantas para utilização 
em Engenharia Natural devem preferencialmente utilizar como substrato solos pobres em nutrientes, visto que a Engenharia Natural utiliza plantas de grande rusticidade e capacidade de desenvolvimento em solos pobres em nutrientes, tornando sua adubação desnecessária ou pouco indicada.

TABELA 2: Características básicas do solo utilizado na composição dos Canteiros Experimentais.

TABLE 2: Basic characteristics of the soil used in the Experimental Plots.

\begin{tabular}{|c|c|c|c|c|c|c|c|c|}
\hline Textura & $\% \mathrm{MO}$ & $\mathrm{pH} \mathrm{H}_{2} \mathrm{O}$ & ind. SMP & $\mathrm{Ca}^{2+}+\mathrm{Mg}^{2+}$ & $\mathrm{Ca}^{2+}$ & $\mathrm{Al}^{3+}$ & $\mathrm{K}^{+}$ & $\mathrm{P}$ \\
\hline & & & & \multicolumn{3}{|c|}{ - - } & \multicolumn{2}{|c|}{----- $\mathrm{mg} \mathrm{kg}^{-1}$} \\
\hline 3 & 2 & 4,6 & 4,9 & 1,2 & 1,3 & 4,4 & 36 & 2,5 \\
\hline
\end{tabular}

Com a ajuda de uma retroescavadeira, os canteiros foram construídos com cerca de 1,7 $\mathrm{m}$ de altura, $5 \mathrm{~m}$ de largura e com 25 a 30 metros de comprimento. Foram orientados no sentido norte-sul, para que as faces de plantio recebessem exposição leste e oeste. Cada lado dos canteiros apresentava duas linhas de plantio (detalhe Figura 1).

Os canteiros experimentais foram divididos em quatro partes que receberam 24 estacas de cada espécie (96 estacas de cada espécie no total), distribuídas nas duas faces de exposição e nas duas linhas de plantio. As estacas de cada espécie com diâmetros entre 1 a $6 \mathrm{~cm}$ e $40 \mathrm{~cm}$ de comprimento foram enterradas em $3 / 4$ do seu comprimento e a uma distância de $25 \mathrm{~cm}$ entre elas. Após o plantio, os canteiros foram cobertos com palha de arroz, a fim de manter a umidade e dificultar o crescimento da vegetação espontânea. Na Figura 1 pode ser visto, como exemplo, o croqui do segundo Canteiro Experimental.

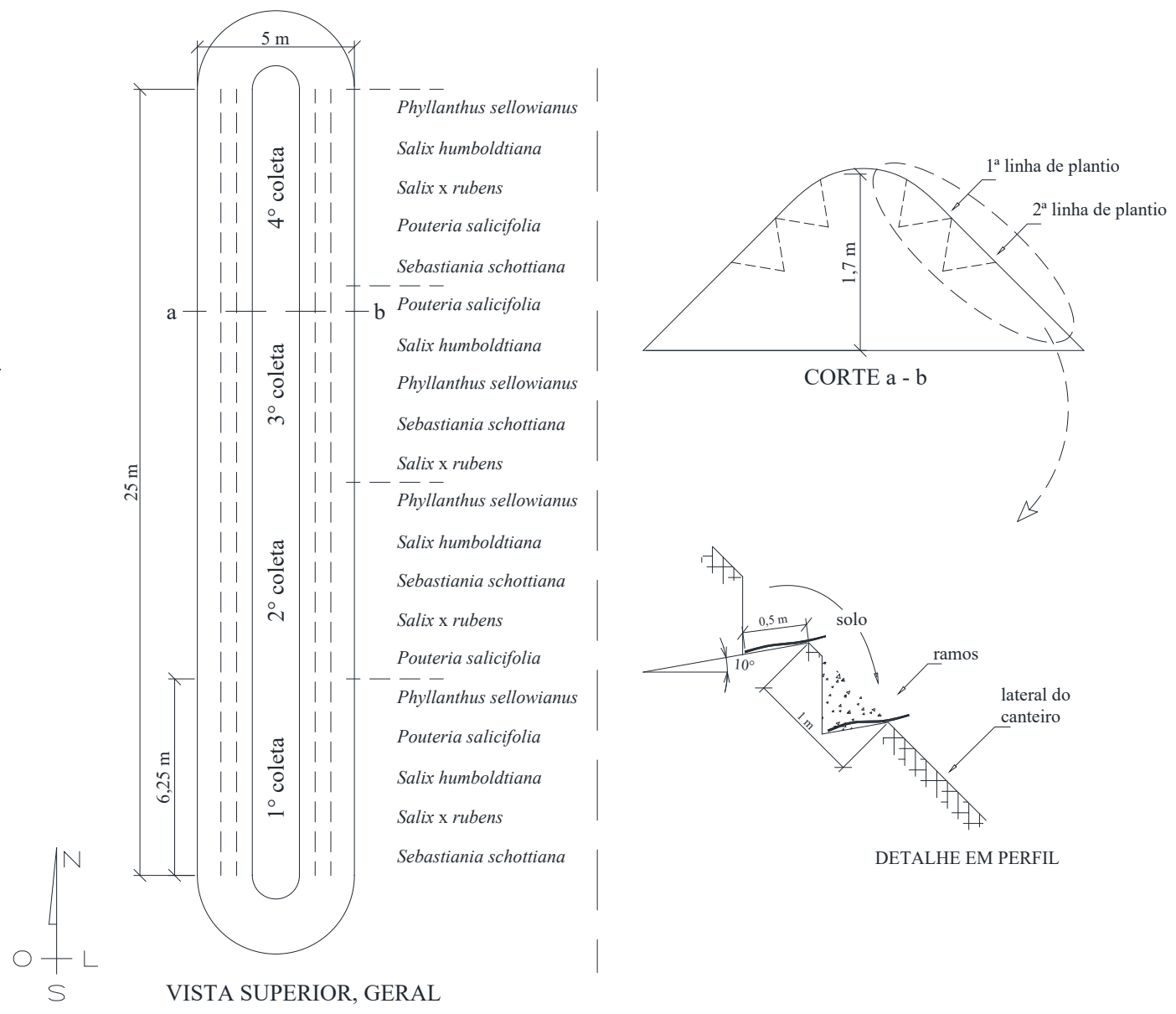

FIGURA 1: Canteiro Experimental.

FIGURE 1: Experimental Plot. 
$\mathrm{O}$ ataque de formigas foi controlado por inspeções diárias e aplicação de iscas formicidas. Uma irrigação diária foi realizada durante a primeira semana, para aumentar as chances de sobrevivência das estacas. As coletas de dados foram realizadas a 60, 90, 120 e 150 dias após o plantio. A cada coleta, as estadas (plantas) de cada espécie foram escavadas sob leve pressão d'água.

O primeiro dado levantado foi a taxa de sobrevivência, obtida pelo número de estacas (plantas) vivas, multiplicado por 100 e dividido pelo número total de estacas plantadas (vivas + mortas). Das plantas vivas foram anotadas as seguintes informações:

- estaca: comprimento total e enterrado; diâmetro da base, meio e ponta.

- brotos: número e comprimento dos brotos primários.

- raízes: número e comprimento das raízes primárias.

De posse destes dados foram calculadas as seguintes variáveis para cada espécie:

- Número médio de brotos por planta, resultado do número total de brotos dividido pelo número de estacas vivas.

- Comprimento médio dos brotos, obtido pelo somatório do comprimento de todos os brotos dividido pelo número total de brotos.

- Média da soma do comprimento dos brotos por planta, resultado da soma do comprimento de todos os brotos dividido pelo número de estacas vivas.

- Número médio de raízes primárias por planta, obtido pelo número total de raízes dividido pelo número de plantas vivas. Também foi calculado o número de raízes por metro de estaca enterrada, obtido pelo número total de raízes dividido pelo somatório do comprimento enterrado de todas as estacas vivas (a fim de facilitar comparações com estudos nos quais o tamanho da estaca utilizada não for o mesmo).

- Comprimento médio das raízes primárias, obtido pelo somatório do comprimento de todas as raízes dividido pelo número de raízes.

- Média da soma do comprimento das raízes primárias por planta, obtido pelo somatório do comprimento de todas as raízes dividido pelo número de estacas vivas. Essa variável também foi calculada por metro de estaca enterrada: média da soma do comprimento das raízes por metro de estaca enterrada, obtida pelo somatório do comprimento de todas as raízes primárias dividido pelo somatório do comprimento enterrado de todas as estacas vivas.

Os dados obtidos foram submetidos à análise de variância e a comparação entre as médias das variáveis de sobrevivência, média da soma do comprimento dos brotos por planta e média da soma do comprimento das raízes primárias por planta nos diferentes períodos do ano foram analisadas separadamente para cada uma das espécies testadas pelo teste de Tukey $(\mathrm{P}<0,05)$.

\section{RESULTADOS E DISCUSSÕES}

Para avaliação do desenvolvimento vegetativo das espécies estudadas, considerou-se como valor da taxa de sobrevivência satisfatório $\geq 70 \%$ (SCHIECHTL, 1973; CORNELINI; FERRARI, 2008).

Na parte superior da Figura 2, ao lado do nome de cada uma das espécies é expressa em valor percentual a taxa de sobrevivência após 150 dias do plantio, nos três períodos de avaliação.

Com exceção de Pouteria salicifolia (avaliada somente no segundo período) todas as outras espécies tiveram taxa de sobrevivência que, segundo os critérios adotados, podem ser considerados entre bons e excelentes.

No entanto, somente a taxa de sobrevivência não é informação suficiente para confirmar a aptidão biotécnica de uma espécie. Assim, a Figura 2 mostra também o valor médio da soma do comprimento e do número de brotos por planta, bem como o valor médio da soma do comprimento e do número de raízes por metro de estaca enterrada. Todos esses valores refletem a média das estacas sobreviventes, após 150 dias.

Entre as quatro espécies avaliadas no primeiro canteiro experimental, Phyllanthus sellowianus e Salix humboldtiana foram as que mostraram a maior produção de raízes e brotos. Levando-se ainda em 
consideração suas ótimas taxas de sobrevivência neste período, pode-se afirmar que estas espécies são capazes de imprimir o ritmo de desenvolvimento vegetativo esperado nas intervenções biotécnicas. Apesar de Sebastiania schottiana ter mostrado tanto taxas de sobrevivência como também produção de brotos e raízes menores, seus resultados são ainda suficientes para qualificá-la como espécie importante. Somente Calliandra brevipes deve ser tomada com ressalvas, pois apesar de uma sobrevivência considerável, conforme já observavam Lorenzi e Sousa (1995), a quantidade de raízes produzidas após 150 dias, foi menor em relação a outras espécies testadas. A falta de uma quantidade expressiva de raízes após cinco meses é informação que, a princípio, compromete o uso desta espécie através da propagação vegetativa. Porém, deve ser lembrado que esta espécie foi avaliada somente no primeiro canteiro experimental.

No segundo período de avaliação, que compreendeu o final do verão e o outono, e o início do inverno, Calliandra brevipes não foi avaliada. Em compensação, duas novas espécies foram incluídas no programa de testes: Salix x rubens e Pouteria salicifolia.

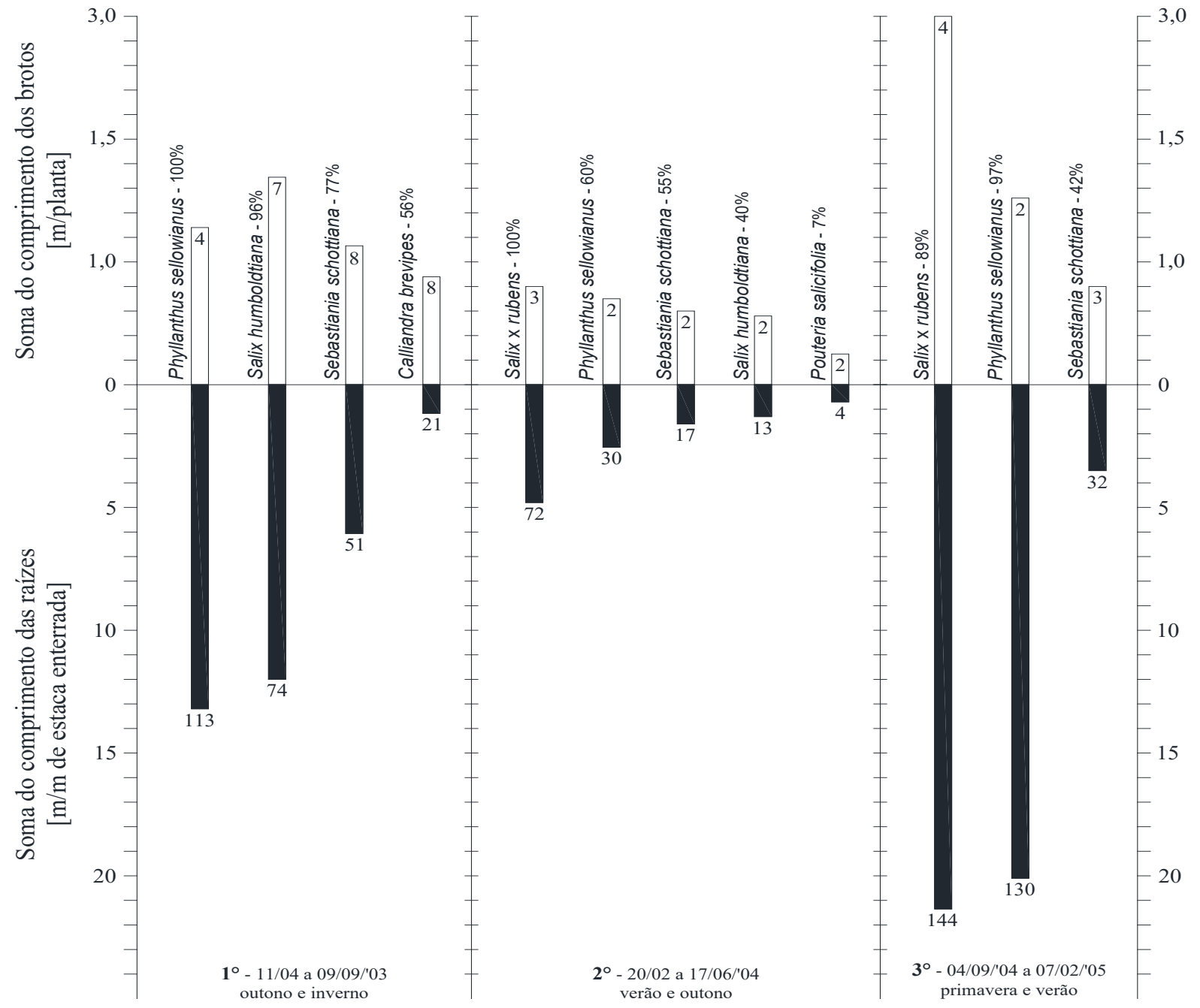

FIGURA 2: Comportamento vegetativo das espécies nos três períodos de avaliação, após 150 dias do plantio. As barras superiores mostram a média da soma do comprimento dos brotos por planta, dentro da barra indica-se o número médio de brotos por planta. As barras inferiores mostram a média da soma do comprimento das raízes por metro de estaca enterrada, o número abaixo indica a quantidade de raízes por metro de estaca enterrada. O percentual ao lado do nome das espécies refere-se à taxa de sobrevivência.

FIGURE 2: Growing vegetative behavior of species in the three assessment periods, after 150 days of planting. The upper bars show the average sum of the shoots length per plant, inside of the bar is the average number of shoots per plant. The below bars show the average sum of the roots length per metre of buried cutting, the low number indicates the number of roots per metre of buried cutting. The percentage next to the species name shows to the survival rate. 
Dentre os três períodos de avaliação, o segundo, que compreendeu o final do verão/outono e início do inverno, foi o que apresentou os menores resultados para as espécies testadas. Isto, por outro lado, evidenciou os bons resultados obtidos por Salix x rubens, que, neste período, teve uma taxa de sobrevivência de $100 \%$.

$\mathrm{Na}$ terceira avaliação teve-se como principal objetivo verificar se a coleta de material vegetal e plantio no período do final do inverno e início da primavera, tido como o ideal para a reprodução vegetativa de plantas em regiões temperadas e subtropicais, iria realmente produzir os melhores resultados. Para isso foram reavaliadas três espécies que já haviam mostrado bons resultados nos experimentos anteriores, a saber: Phyllanthus sellowianus, Salix x rubens e Sebastiania schottiana. Os resultados para as duas primeiras espécies confirmam o presumível melhor desenvolvimento neste período. Por outro lado, Sebastiania schottiana chamou atenção ao mostrar resultados menos promissores que os conseguidos no canteiro implantado no período do outono e inverno.

Todas as espécies apresentam um alto desvio padrão no comprimento das suas raízes (veja exemplo na Figura 3), o que é esperado, dado o simples fato que após cinco meses se tem um número de raízes que já se desenvolve por todo esse tempo e um número ainda maior que vem se desenvolvendo somente a partir dos últimos meses, ou dias. Os valores médios são pouco expressivos quando comparados com o comprimento máximo alcançado por uma porcentagem das maiores raízes. Por exemplo, uma planta de Salix humboldtiana que após cinco meses possui raízes que na média alcançam $16 \mathrm{~cm}$, possui cerca de $3 \%$ de suas raízes com mais de $75 \mathrm{~cm}$ de comprimento. Mesmo essa porcentagem sendo pequena, revela que existem raízes longas capazes de ancorar linhas de fratura a certa distância até neste período inicial do desenvolvimento vegetativo. As raízes finas e numerosas se concentram nas primeiras camadas de solo e são capazes de aumentar a resistência ao cisalhamento do solo nessa área, as mais longas, apesar de uma ação mais localizada, também produzem efeito de estabilização ancorando linhas potencias de fratura do solo.

A Figura 3 mostra, a título de exemplo, a distribuição dos comprimentos das raízes de humboldtiana para todas as raízes mensuradas para a espécie, durante a última avaliação (primavera e verão).

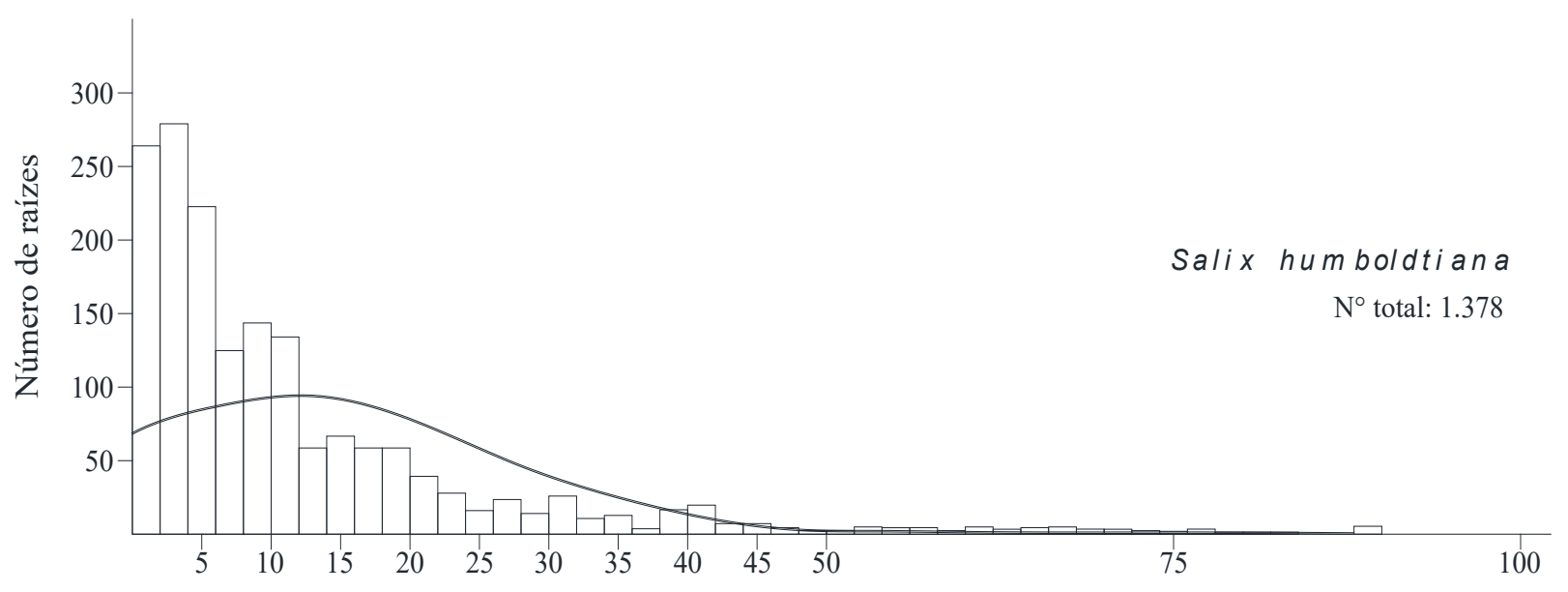

FIGURA 3: Número de raízes de Salix humboldtiana por classe de comprimento, na última avaliação (após 150 dias).

FIGURE 3: Number of roots of Salix humboldtiana per length class, in the last evaluation (150 days).

A Figura 4 mostra o comprimento médio dos brotos e raízes de Salix humboldtiana, durante o desenvolvimento dos dois experimentos. 


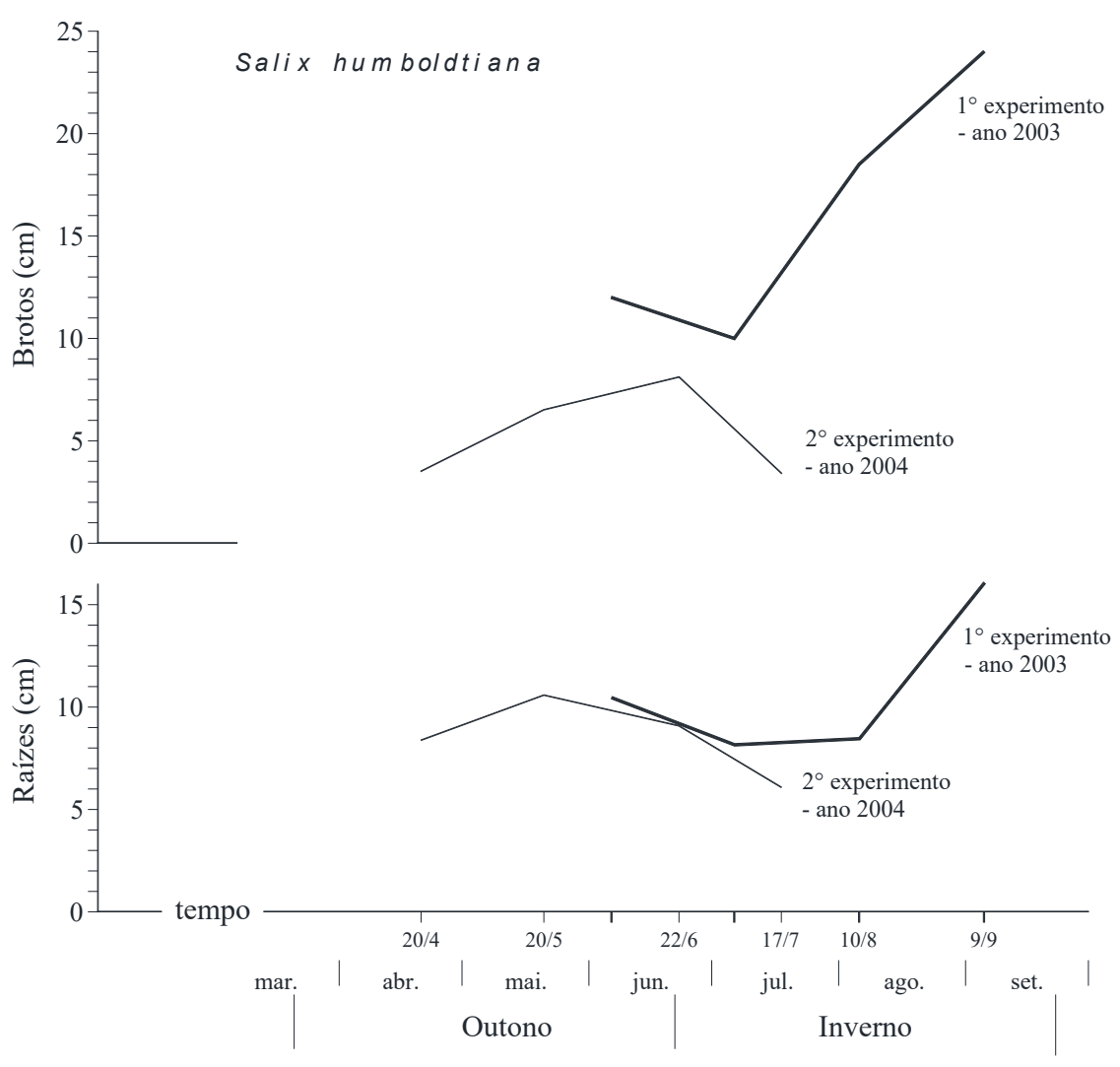

FIGURA 4: Ritmo vegetativo de Salix humboldtiana.

FIGURE 4: Vegetative rate of Salix humboldtiana.

No primeiro experimento, o plantio foi feito no dia 11 de abril e a primeira coleta de dados dois meses após, no dia 11 de junho. A segunda coleta realizada a um mês da primeira mostrou plantas com menor comprimento de brotos e raízes que na primeira. No entanto, essa tendência logo se inverteu com a chegada de condições climáticas melhores. Também é evidente na Figura 4 como o crescimento radicular é retomado com atraso em relação ao desenvolvimento da parte aérea. O segundo experimento foi iniciado no dia 20 de fevereiro e a primeira coleta de dados que ocorreu no dia 20 de abril mostra valores bem aquém dos conseguidos no primeiro experimento. Mesmo assim, ocorre um desenvolvimento lento até o primeiro mês de inverno e que é logo estagnado e decresce com a entrada do inverno. Ainda com uma clara e forte perda de vigor no último mês, mês, Phyllanthus sellowianus, Salix humboldtiana, Salix x rubens e Sebastiana schottiana foram capazes de um crescimento radicular que lhes garantiria sobrevivência até a retomada do desenvolvimento. Figura 4 para Salix humboldtiana.

Retornando-se à Figura 2, é possível se chegar ao comprimento médio das raízes dividindo o somatório do comprimento (brotos ou raízes, mostrado pelo comprimento das respectivas barras) pelo número médio de brotos ou raízes. Esse valor médio, no entanto, não traz muita informação e pode, inclusive, levar a graves erros de julgamento sobre a capacidade biotécnica das plantas.

Mais esclarecedora é a análise da distribuição das raízes por classe de tamanho. Para as três espécies estudadas no último canteiro, essa análise foi feita e é mostrada na Figura 5. A ilustração foi realizada com base nos dados médios das plantas sobreviventes de cada espécie após 150 dias. Na ilustração podem ser lidas informações como: $40 \%$ das raízes de Phyllanthus sellowianus são capazes de ultrapassar os $25 \mathrm{~cm}$ de comprimento, contudo, somente $11 \%$ do total das raízes ultrapassam o limite de $40 \mathrm{~cm}, 3 \%$ chegam aos $60 \mathrm{~cm}$ e somente $1 \%$ das raízes consegue atingir valores maiores que $80 \mathrm{~cm}$. Interpretação análoga pode ser feita para Salix x rubens e Sebastiania schottiana.

Ficou evidente, durante a coleta de dados, que Phyllanthus sellowianus desenvolveu um sistema radicular muito mais fasciculado do que Salix x rubens, como deixa entender a Figura 5. Da mesma maneira, Phyllanthus sellowianus mostrou quantidade maior de brotos secundários que não tiveram seus comprimentos mensurados. 


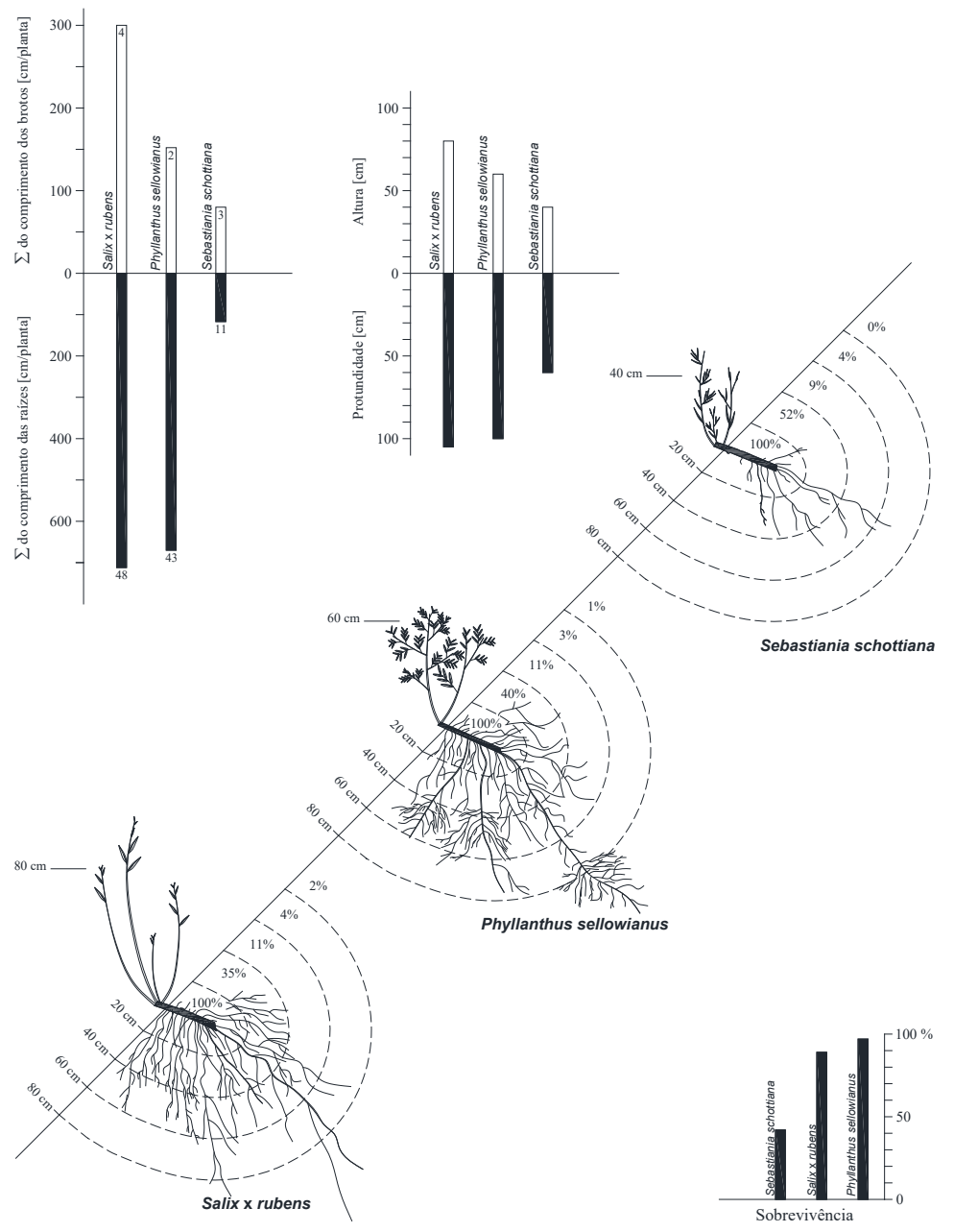

FIGURA. 5: Comportamento vegetativo de estacas de Salix x rubens, Phyllanthus sellowianus e Sebastiania schottiana plantadas em setembro de 2004 e avaliadas 150 dias após (fevereiro de 2005). Os gráficos acima mostram o somatório do comprimento e o número de brotos e raízes por planta. A representação gráfica (desenho) das três espécies mostra a distribuição percentual das raízes nas diferentes profundidades do solo. O padrão arquitetônico dos sistemas radiculares foi representado com base no observado durante a coleta de dados. O gráfico no canto inferior direito mostra a taxa de sobrevivência após 150 dias.

FIGURE 5: Vegetative behavior of Salix x rubens, Phyllanthus sellowianus and Sebastiania schottiana cuttings planted in September 2004 and evaluated after 150 days (February 2005). The charts above show the sum of the shoots and root lengths and number per plant. The graphical representation (drawing) shows the percentage distribution of roots at different soil depths for the three species. The architectural pattern of root systems was represented based on the observations made during data collection. The chart in the lower right corner shows the survival rate after 150 days.

\section{CONCLUSÕES}

Phyllanthus sellowianus e Salix humboldtiana foram as espécies que mostraram a maior produção de raízes e brotos, além de ótimas taxas de sobrevivência. Pode-se afirmar que estas espécies possuem ritmo de desenvolvimento vegetativo desejado para as intervenções biotécnicas.

Apesar de ter mostrado tanto taxas de sobrevivência como também produção de brotos e raízes relativamente menores, Sebastiania schottiana ainda pode ser considerada importante para os fins biotécnicos, tendo como ponto positivo a sua marcante e ampla distribuição, não só na Região Central do 
Estado, sendo uma das principais representantes das espécies de hábito reófito do sul do Brasil.

Calliandra brevipes deve ser tomada com ressalvas, já que sua propagação vegetativa foi testada somente no período de outono e inverno, quando obteve uma quantidade de raízes pequena apesar de sobrevivência considerável. Para melhores conclusões serão necessários novos experimentos.

Todas as espécies, com exceção de Pouteria salicifolia, tiveram taxa de sobrevivência que, segundo os critérios de Schiechtel (1973), podem ser considerados entre bons e excelentes. Como Pouteria salicifolia foi avaliada somente no período de verão e outono, seria ideal que esta espécie fosse também avaliada em outros períodos.

Dentre os três períodos de avaliação, foi no outono e inverno que as espécies encontraram, de modo geral, menor crescimento. Isto, por outro lado, evidenciou os bons resultados relativos de Salix x rubens.

Phyllanthus sellowianus, Salix x rubens confirmaram que o maior crescimento ocorre no período do final do inverno e início da primavera. Por outro lado, Sebastiania schottiana chamou atenção ao mostrar resultados mais promissores no outono e inverno. A constatação de que os períodos ótimos de desenvolvimento não são coincidentes para todas as espécies é bastante importante do ponto de vista prático, pois amplia a possibilidade de realização de intervenções em diferentes épocas do ano, desde que se considere a espécie ideal para cada momento.

\section{REFERÊNCIAS}

ABATE, I.; GROTTA, M. Ingegneria Naturalistica: costruire con le piante-linee guida all'impiego delle piante negli interventi di ingegneria naturalistica in ambito mediterraneo. Benevento: Lume, 2009.

ALTREITER, W.; PLUNGER, K. Ingenieurbiologische Maßnahmen am Rio Guarda-mor in Südbrasilien: untersuchung der Biologisch-technischen Eigenschaften von Ufergehölzen. Wien: Diplomarbeit, Universität für Bodenkultur; Department für Bautechnik und Naturgefahren, Institut für Ingenieurbiologie und Landschaftsbau, 2004.

BERTOLINI, D.; LOMBARDI NETO, F. Embasamento técnico do Programa Estadual de Microbacias Hidrográficas. In: LOMBARDI NETO, F.; DRUGOWICH, M. I. (Coord.). Manual técnico de manejo e conservação de solo e água. Campinas: CATI, 1994. $15 \mathrm{p}$ (Manual Técnico, 38).

COMISSÃO DE QUÍMICA E FERTILIDADE DO SOLO. Manual de adubação e calagem para os Estados do Rio Grande do Sul e de Santa Catarina. 10. ed. Porto Alegre: Sociedade Brasileira de Ciência do Solo, 2004. 400 p.

CORNELINI, P.; FERRARI, R. Manuale di ingegneria naturalistica per le Scuole Secondarie. Roma: Regione Lazio, 2008.

DENARDI, L. Anatomia e flexibilidade do caule de quatro espécies lenhosas para o manejo biotécnico de cursos de água. 2007. $113 \mathrm{f}$. Tese (Doutorado em Engenharia Florestal) - Universidade Federal de Santa Maria, Santa Maria, 2007.

DURLO, M. A.; SUTILI, F. J. Bioengenharia - Manejo biotécnico de cursos de água. Santa Maria: EST, 2005.

FLORINETH, F. Pflanzen statt Beton. Handbuchzur Ingenieurbiologie und Vegetationstechnik. Berlin: PatzerVerlag, 2004.

FLORINETH, F.; GERSTGRASER, C. Ingenieurbiologie. Wien: Institut für Landschaftsplanung und Ingenieurbiologie, Universität für Bodenkultur, 2000.

GRAY, D. H.; LEISER, A. T. Biotechnical slope protection and erosion control. Florida: Krieger Publishing Company Malabar, 1982.

LORENZI, H.; SOUSA, H. Manual de plantas ornamentais no Brasil: arbustivas, herbáceas e trepadeiras. Nova Odessa: Plantarum, 1995.

MENEGAZI, G.; PALMERI, F. II dimensionamento delle opera di ingegneria naturalística. Direzione Regionale Infrastruture, Ambiente e Politiche abitative. Roma: Regione Lazio, 2013.

MORGAN, R. P. C.; RICKSON, R. J. Slope stabilization and erosion control: a bioengineering approach. London: E \& FN Spon, 1995.

PIMENTEL, D. et al. Environmental and economic costs of soil erosion and conservation benefits. Science, Washington, v. 267, n. 5201, p. 1117-1123, 1995. 
REZENDE, A. A. Enraizamento de estacas de Candeia (Eremanthus erythropappus (DC.) MacLeish). 2007. 75 f. Dissertação (Mestrado em Engenharia Florestal) - Universidade Federal de Lavras, Lavras, 2007.

SAULI, G.; CORNELINI, P.; PRETI, F. Manuale d'ingegneria naturalistica applicabile al settore idraulico. Roma: Regione Lazio, 2002.

SCHIECHTL, H. M. Bioengegneria Forestale. Basi: materiali da construzione vivi - metodi. Feltre: Tipolitografia Castaldi, 1973. 263 p.

SCHIECHTL, H. M. Handbuch für naturnahen Erdbau: eine einleitung für ingenieurbiologische Bauweisen. Wien: Österreichischer Agrarverlag, Druck und Verlagsgesellschaft m.b.H., 1992.

SCHIECHTL, H. M.; STERN, R. Handbuch für naturnahen Wasserbau: eine einleitung für ingenieurbiologische Bauweisen. Wien. Wien: Österreichischer Agrarverlag, Druck und Verlagsgesellschaft m.b.H., 1994.

SUTILI, F. J.; DURLO, M. A. Bioengenharia de Solos: o estado da arte na Europa e no Sul do Brasil. Conselho em revista, Porto Alegre, v. 3. n. 32, abr. 2007. 